\title{
Demand vs consumption - Analysing the energy certification for buildings
}

Received (in revised form): 3rd August, 2007

\section{David Steixner}

finished his studies of Facility Management at the University of Applied Sciences in Kufstein in 2005. Since 2005, he has been a research fellow at the University of Applied Sciences in Kufstein, where he is currently carrying out a Research Project in the field of Real Estate Benchmarking. In parallel, he started his PhD studies in 2006 at the University of Innsbruck.

\section{Wolfgang Brunauer}

started his PhD studies at the University of Innsbruck in 2004, where he also began his studies of Economics and Mathematics following his studies of Facility Management at the University of Applied Sciences in Kufstein. Since 2005, he has been a research fellow at the University of Applied Sciences in Kufstein, where he is currently carrying out a Research Project in the field of Real Estate Benchmarking. Wolfgang Brunauer was awarded several prizes, for example, the Emerald Gerald Brown Award 2006 and awards by the IFMA, Gefma and DVP.

\section{Stefan Lang}

earned his diploma in statistics in 1997 and his PhD in Statistics in 2001, both at the University of Munich, where he habilitated in 2004. Having worked as a research assistant until 2002, he became an assistant professor at the Department of Statistics of the University of Munich. In 2005, he became a Professor of Statistics at the University of Leipzig. In 2006, he became a Professor of Statistics at the University of Innsbruck.

Correspondence: David Steixner, FHS Kufstein Tirol BildungsGmbH, University of Applied Sciences, Andreas Hofer Strasse 7, Kufstein A-6330, Austria; Tel: + 43 (0) 537271819 129; Fax: + 43 (0) 537271819 104; E-mail: David.Steixner@fh-kufstein.ac.at; Web: www.fh-kufstein.eu and www.immobilien-benchmarking.at

\begin{abstract}
The directive 2002/91/EC of the European Parliament and the Council of 16th December, 2002 (Energy Performance of Buildings Directive, EPBD, 2002) requires member states to introduce an energy certification in order to reduce energy consumption in buildings. For the appraisal of the energy, key-figure paragraph 2 of the directive generally allows both the theoretical calculation of energy demand and the collection of the real energy consumption; however, these two approaches do not always lead to the same result, but rather to substantially different values. Naturally, this leads to lively discussions among the involved persons. This paper is the first survey of a study whose goal is to explain where the differences between the two approaches arise from. The first results, for example, show that external walls, ceilings and roofs with a theoretically poor thermal quality are expected not to be as 'bad' in practice as the theoretical calculation would lead us to believe.

Journal of Building Appraisal (2007) 3, 213-229. doi:10.1057/palgrave.jba.2950076
\end{abstract}

\section{Keywords:}

energy certification, heating energy, directive 2002/91/EC, residential buildings, linear regression model

\section{INTRODUCTION}

The Energy Performance of Buildings Directive (EPBD, 2002) of the European

Parliament and the Council of 16th December, 2002 should help reveal saving potentials 
in real estate in order to achieve the aim of the Kyoto Protocol. It will surely set off an impulse for energy-efficient restructuring of buildings. The transparency concerning energy consumption of buildings will inevitably apply to all property transactions and lease prices of buildings.

As the directive allows the theoretical calculation of the energy demand as well as the practical collection of the energy consumption, in some EU member states lively discussions started regarding which approach should be executed. Both have their advantages (or disadvantages, respectively): Data collection of consumption costs about $75 €$ per building and therefore is much cheaper than theoretical calculation, which costs between $150 €$ and $300 €$ (Hegner, 2004; DENA, 2005). The reason is that for the theoretical approach, considerable amount of data have to be collected and the methodology also requires the know-how of experts to be carried out. On the other hand, the theoretical approach is more like a neutral evaluation of the energy quality of buildings because it is based on normative assumptions. Furthermore, the habits of the dwellers do not influence the result of this approach (Hegner, 2004).

\section{OBJECTIVE AND STRUCTURE OF THIS PAPER}

This paper is the first survey of a study on the comparison of both approaches. It is easy to show that the results differ fundamentally in many cases. This 'gap' between the two approaches is analysed in a comprehensive study, focusing on the heating energy figures. Therefore, the annual heating energy consumption (HEC) of 100-200 Austrian buildings will be collected. Simultaneously, the theoretical demand-oriented calculation will be carried out in order to compare and analyse the differences in the results of the two approaches. This first part of the study contains the analysis of 33 residential buildings. Statistical analysis helps to reveal the sources of the partly extensive differences in the results. Therefore, the analysis will show whether the methodology for calculating the theoretical heating demand represents the real energy budget of buildings.

The rest of the paper is organised as follows. The next section deals with a description of the data. In the following section, the calculations are specified, which are necessary to make the HEC comparable to the heating energy demand. The derivation of the influencing factors on the gap between demand and consumption is also described in this section. In a further section the first results of this project are presented and the last section summarises the content of this survey.

\section{DESCRIPTION OF THE DATA}

As already mentioned, data of 100-200 multifamily residences in Austria will be collected in total. Actually, data of 33 buildings have been collected and analysed (see the section Results: Mean comparison test - HEC vs DTH), and about 70 objects of three further building societies will be integrated into the survey in the near future. In order to compare the theoretical to the actual energy demand, two types of indicators are necessary, namely the energy consumption and theoretical energy demand - both are described in the following sections. The percentage difference between these two key figures is the dependent variable in the regression model described in the section Derivation of hypotheses. Furthermore, we need variables explaining this difference. These variables are described in the section Description and calculation of the explanatory variables. 


\section{Demand of thermal heat}

The demand of thermal heat (DTH) is the amount of heat that has to be provided to keep the temperature of the heated rooms at the required level (OIB, 2005). This value is calculated theoretically according to the construction physics and other characteristics of the building. For the calculation of this value, several algorithms are defined. In this survey, the algorithm according to the Austrian Institute for structural engineering (OIB, 2004) is applied. The DTH must not be confused with the energy performance of buildings, which is defined by the European Parliament. The difference is that the demand of thermal heat is just a part of the energy performance indicator, because energy-relevant aspects such as the efficiency of the heating system, the cooling system and lighting are not considered. At this point of time, it is not possible to analyse the whole energy performance, because in Austria as well as in many other European states, the algorithm for calculation is not defined conclusively.

\section{Heating energy consumption}

The HEC is the amount of heating energy a heating system spends within one year for hot water supply and for maintaining the temperature of a building at the required level (Cerveny et al., 2004).

\section{Description and calculation of the explanatory variables}

Thermal loss due to components that adjoin unheated rooms (bt_u) is the energy that 'gets lost' within one year per square metre (gross floor area) through, for example walls, columns or ceilings that are conterminous to rooms of buildings that are not heated.

Thermal loss due to components that adjoin to the outside (bt_a) is in principle the same as 'bt_u', except that these components are not conterminous to unheated rooms but to the outside. Hence these components are directly exposed to the weather. Examples of such components are outside walls, ceilings and the roof.

Thermal losses due to windows and doors $\left(f_{-} t\right)$. This figure covers the heating energy losses per square metre (gross floor area) and year through windows and doors that adjoin unheated rooms, as well as thus that adjoin the outside.

Thermal gains due to solar radiation ( $\mathrm{sol}$ ) constitute the solar energy that comes through glass elements as for example windows or glass facades. This figure also refers to the energy within one year per square metre (Gross floor area).

Thermal losses due to heating bridges ( $l w_{-} z$ ) are the heating energy losses that are determined by thermal weak spots in the building shell referring to the same unit as the other variables.

Gross floor area of the building (size) - self-explanatory Age of the building (age) - self-explanatory

As already explained, the main objective of this study is to analyse the difference between $\mathrm{HEC}^{1}$ and DTH. Hence, it is necessary to have detailed figures of all variables that could have an influence on the difference, to be able to draw meaningful conclusions. Therefore, we divided the demand of heating energy into a number of key-figures. This means that we calculated how much energy loss (or energy gains) are caused by 
several factors, which have an influence on the heating energy budget of a building. In other words, we calculated for each building as to how much heating energy gains/ losses per square metre and year the several factors cause. The basis for these calculations was the data of the heating energy certification of the buildings, which were calculated by the program of the Austrian institute for structural engineering. For the calculation of bt $\mathrm{u}, \mathrm{bt} \_\mathrm{a}, \mathrm{f} \_\mathrm{t}$ and lw_z, we used the heat conductance of the several components. Applying the following formula, the gains/losses through the corresponding component per square metre and year were calculated. The calculation of 'sol' was much easier because for this figure the gains per year $(\mathrm{kWh} / \mathrm{a})$ are explicitly calculated, and so it was only necessary to divide this value by the gross floor area.

$$
H L_{\text {comp }}=\frac{G_{\text {th }}}{A_{\text {comp }}} * D G D_{2005} * 0,024
$$

$H L_{\text {comp }}$ is the heating losses through the several components (bt_u, nt_a, f_t, lw_z), $G_{t h}$ the heat conductance of the component,

$A_{\text {comp }}$ the area of the component and

$D G D_{2005}$ is the degree days in the corresponding region in the year of issuing the energy certification.

\section{Overview of all variables}

Table 1 shows the details for all variables that are included in the analysis.

\section{COMPARABILITY OF THE DTH AND HEATING ENERGY CONSUMPTION}

Looking at the definitions of the HEC and the demand of thermal heating energy, respectively, it becomes clear that these two figures cannot be compared directly. The reason is that the consumption depends on factors such as the annual variation in atmospheric conditions, the consumption of hot water and the efficiency of the heating system, whereas the demand is just a 'norm consumption' calculated from the physical characteristics of a building. Figure 1 shows the difference between these two indicators. The left column represents the demand, which consists of the transmittance heat losses through the building shell and the ventilation losses caused by leaks in the building shell as well as natural or artificial ventilation. The heat gains from solar radiation and from internal heat sources like occupants or electronic equipment that produce heat reduce the DTH. The right column shows the HEC. Solar gain, internal gain, ventilation losses and transmittance losses are the same as in the demand column. Differences accrue regarding the losses through the heating system, the 'gains' or 'losses' from variations in the weather and in some cases regarding the hot water supply.

To make the two indicators comparable, it is necessary to calculate the adjustment concerning the weather and the losses due to the heating system and the hot water supply.

$H E C_{a d j}=H E C_{\text {weather }}-H L$

HEC $_{a d j}$ is the adjusted heating energy consumption,

$H E C_{\text {weather }}$ the heating energy consumption adjusted by the variation in weather and $H L$ and the heating losses due to the heating system.

The following paragraphs describe how the different factors are considered in the calculation. 


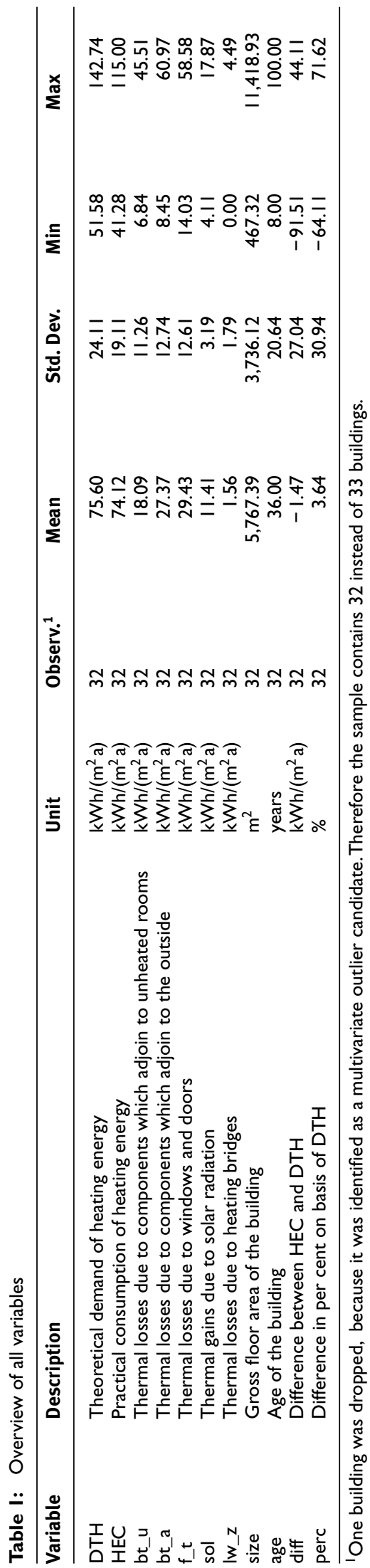




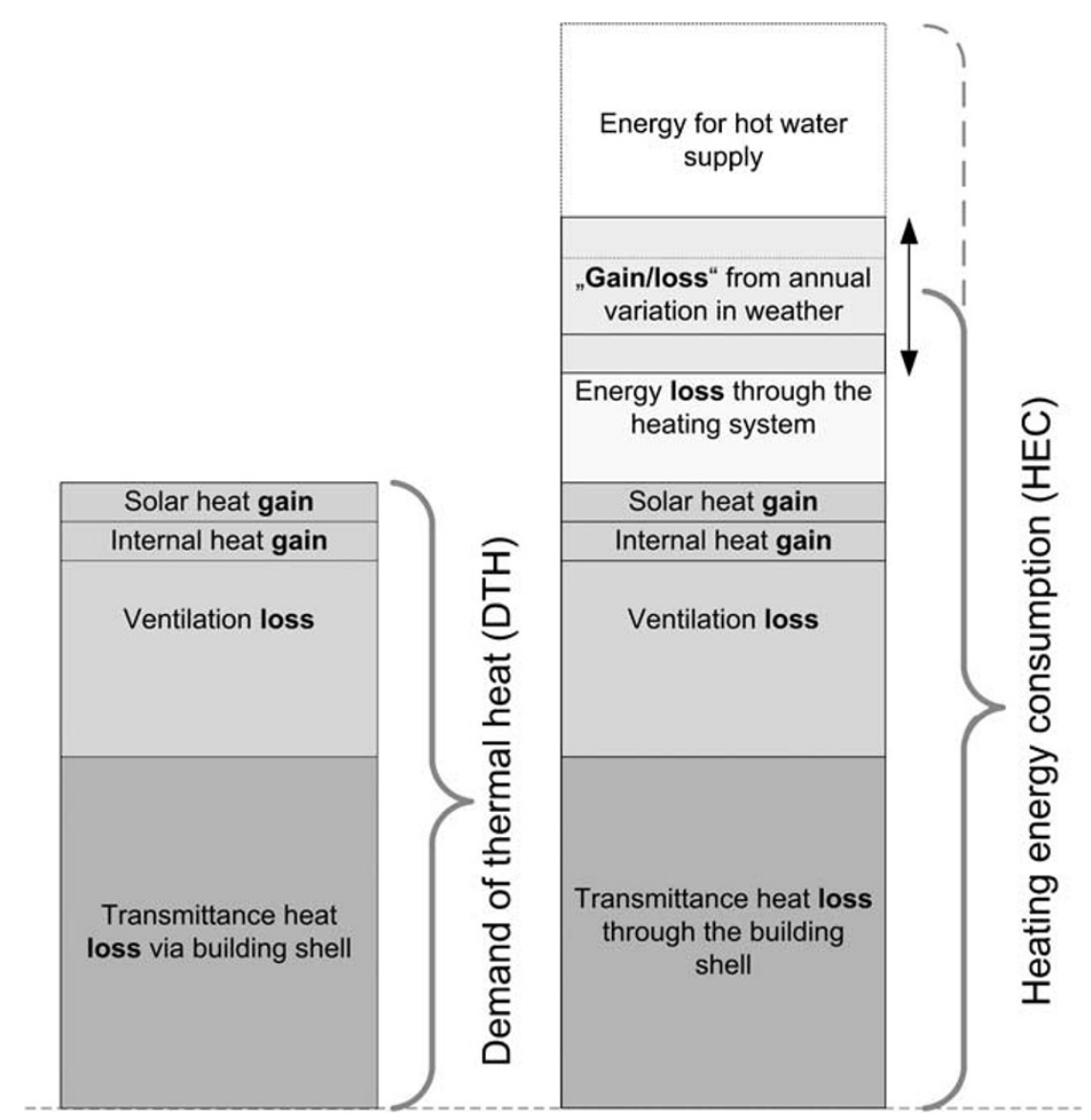

Figure I: Comparison of demand and consumption

\section{Considering the annual variation in weather}

Naturally, the amount of heating consumption also depends on the temperature during a heating period, because consumption of heating energy in a relatively 'cold' winter is likely to be substantially higher than in a 'norm' or 'warm' winter. The calculation of the energy certification of a building is based on a 'norm winter'. Therefore, the heating periods of the survey years (2000-2005) must be adjusted to the norm temperature that is used for DTH calculation. For the derivation of the factor for the adjustment of DTH and HEC, we used an indicator that is called degree day (HGT). This figure is published by ZAMG (Zentralanstalt für Meteorologie und Geodynamik: ZAMG, 2006) every year for all Austrian villages. Degree days depend on two parameters: the theoretical room temperature and the heating limit for the outdoor temperature as well as the average outdoor temperature of the relevant region per day (Schöngrundner, 2002). To adjust the HEC to the temperature of the survey year, a factor was calculated by dividing the norm degree days of the region by the degree days of the corresponding years. As all buildings of our sample are in Innsbruck, we used the same factor for all buildings (see Table 2):

$$
\begin{aligned}
& H E C_{\text {weather }}=H E C_{\text {orig }} \times r_{d g} \\
& r_{d g}=\frac{D G D_{\text {norm }}}{D G D_{2000-2005}}
\end{aligned}
$$

$H E C_{\text {orig }}$ is the adjusted heating energy consumption,

$H E C_{\text {weather }}$ the heating energy consumption adjusted by the variation in weather, 
$r_{d g}$ the factor for adjusting the variation in weather,

$D G D_{\text {norm }}$ the norm degree days in the corresponding region and

$D G D_{2000-2005}$ is the mean of degree days in the corresponding region from the year

2000 to 2005.

Table 3 shows the characteristic of the several buildings and the corresponding calculations that were necessary to adjust HEC to DTH. The result of this calculation is the adjusted heating energy consumption $\left(H E C_{a d j}\right)$, which is, with regard to its content, comparable to the DTH.

\section{Energy losses due to the heating system}

Energy losses through the heating system result from the heating generation system (eg combustion plant), the heating storage system, the heating distribution system and the heating elements (Cerveny et al., 2004). For the adjustment of the HEC, a factor was derived, which considers all losses through the heating system (see following Formula). The assumptions for the derivation of the factor are described in detail in the following paragraphs.

$$
\begin{aligned}
& H L=H E C_{\text {weather }} \times r_{\text {htot }} \\
& r_{\text {htot }}=r_{\text {he }}+r_{\text {hds }}+r_{\text {hg }}+r_{\text {hw }}
\end{aligned}
$$

$H L$ are the total heating losses

$H E C_{\text {weather }}$ the heating energy consumption adjusted by the variation in weather, $r_{\text {he }}$ the factor that considers losses through heating elements,

$r_{\text {hds }}$ the factor that considers losses through heating distribution and heating storage,

$r_{\mathrm{hg}}$ the factor that considers losses in heating generation

$r_{\mathrm{hw}}$ the factor that considers the losses due to hot water supply.

$r_{\text {htot }}$ the sum of all factors

\section{Losses through the heating generation system $\left(\boldsymbol{r}_{h g}\right)$}

The main difference in the efficiency of the heating generation systems results from the energy source used. Table 2 shows the different types of heating generation systems and the factors for the several systems.

The efficiency factor lies between 0.022 and 0.152 . The losses that are considered in this factor result from operation losses, stand-by losses and overdimensioning of the generation system. The operation losses depend on the type of the heating generation system. Stand-by losses and losses caused by an overdimensioned system can be reduced when the system operates on its nominal power continuously. In contrast, these losses would increase in case of a high start-stop frequency of the system.

Table 2: Efficiency factors of energy generation systems

\begin{tabular}{ll}
\hline Energy source & Factor $\mathrm{r}_{\mathrm{hg}}$ \\
\hline Pellets & 0.152 \\
District heating & 0.022 \\
Extra light fuel oil & 0.130 \\
Gas $<26 \mathrm{~kW}$ & 0.150 \\
Gas $>26 \mathrm{~kW}$ & 0.128 \\
\hline
\end{tabular}

Source: Vornorm ÖNORM H 5056-I. 


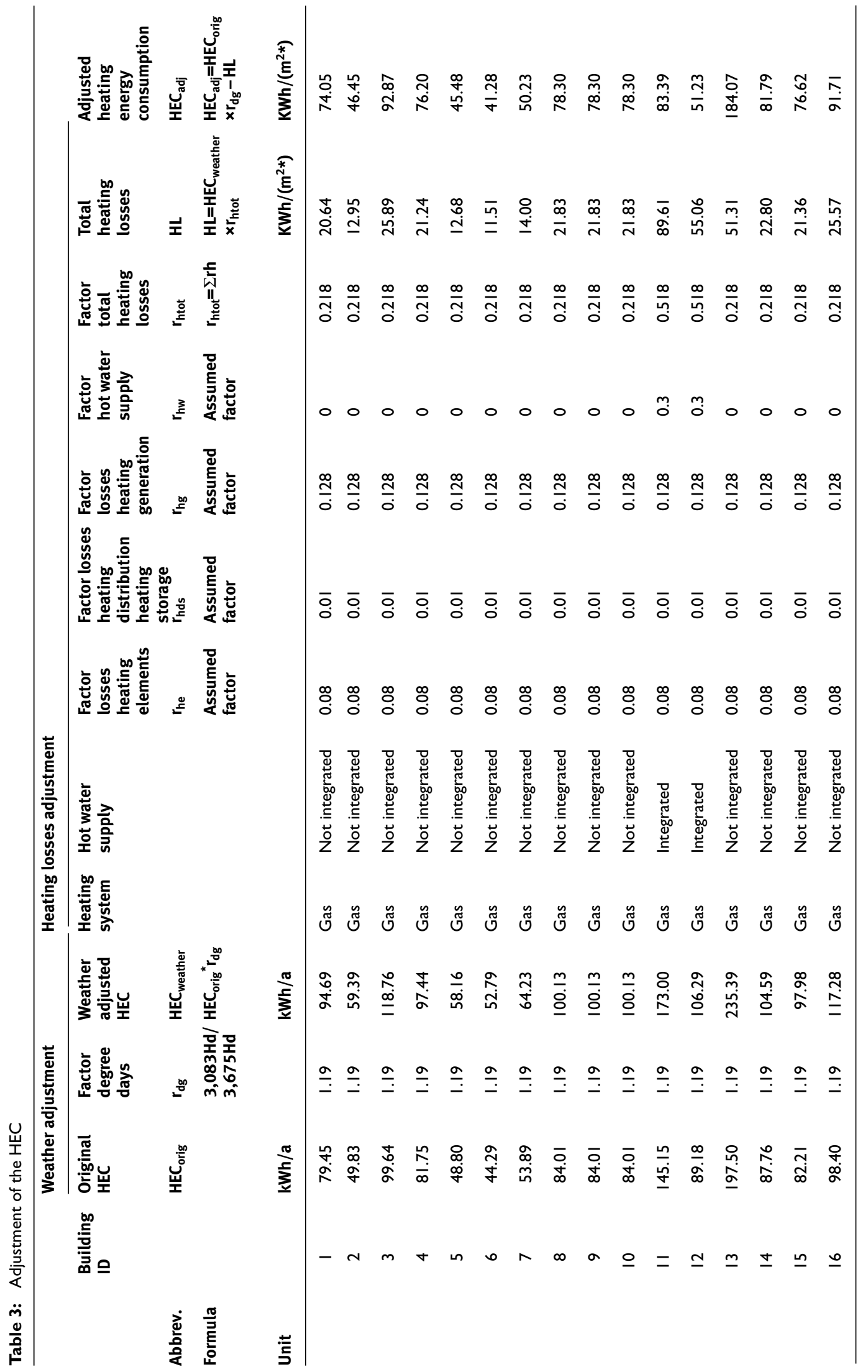




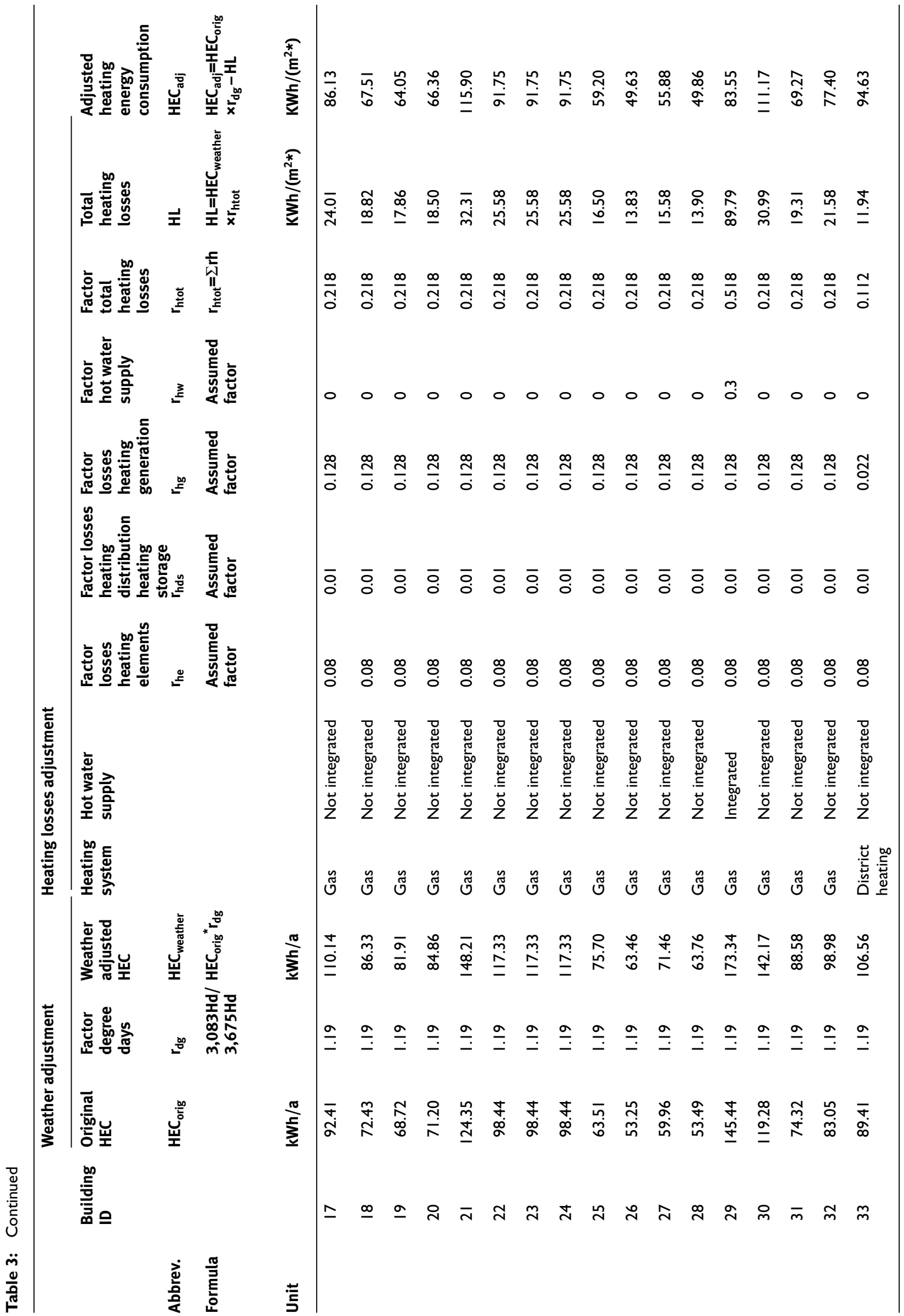




\section{Losses through the heating distribution system and the heating storage system $\left(r_{h d s}\right)$}

A detailed data collection of all influencing factors of the heating distribution system and the heating storage system has not been carried out in this study, because it would have involved substantial efforts. Moreover, the influence of this factor on the HEC is not that determining. Therefore, general assumptions on the basis of the Vornorm ÖNORM H 5056-1 (2004) have been made to derive a general factor for these losses:

- The thermal insulation of the piping corresponds with the diameter of the pipes.

- Most of the piping is within the heated parts of the building, and therefore a part of these losses is 'regainable'.

- The operating temperature is below $55^{\circ} \mathrm{C}$.

- There is no temperature reduction during the night.

- There is no buffer store and no load-compensation facility in the direct room heating.

These general assumptions represent the heating distribution system and the heating storage system of a common multifamily residential building in Austria and lead to a factor of 0.03 .

\section{Losses through the heating elements $\left(\boldsymbol{r}_{\text {he }}\right)$}

Analogous to the last paragraph, the calculation of the efficiency factor for heating elements is based on the Vornorm ÖNORM H 5056-1 (2004). The factor depends on the following characteristics, which are not considered in detail for each subject, but in general assumptions:

- The controllability of the heating elements is regarded to be the adjustability of the room-heating temperature controller. In this study, it is assumed that a conventional residence building is equipped with a single room controller and thermostat valves.

- The heat supply is provided by heating elements with small surfaces (eg radiators).

- The consumption of heating energy also depends on whether it is accounted for according to the real individual consumption of the occupants or according to a fix rate. In this study, an individual accounting system is assumed. ${ }^{2}$

According to these assumptions, the factor for losses due to heating elements is 0.08 .

\section{Energy for hot water supply $\left(\boldsymbol{r}_{\text {hw }}\right)$}

There are two types for hot water generation: The hot water supply can be completely separated from the heating system or it can be integrated into the room heating system. For the first type, we have no problem analysing the HEC, because it does not influence the value. For the second type, we have to discount the amount of energy, which goes into the production of hot water. In this case, the problem is that the amount of room heating energy and the amount of energy for hot water supply is not separately measured in many cases. In our sample, 88 per cent of the buildings have a decentralised system for hot water supply; therefore, an adjustment is not necessary. For the rest of the buildings (12 per cent), a factor of 0.3 is calculated. 


\section{RESEARCH METHOD}

\section{Derivation of hypotheses}

The first question was whether this sample shows a significant difference in the means of DTH and the HEC. This resulted in the following testable hypothesis:

$$
\begin{aligned}
& \boldsymbol{H}_{0}: \mu_{D T H}=\mu_{H E C} \\
& \boldsymbol{H}_{1}: \mu_{D T H} \neq \mu_{H E C}
\end{aligned}
$$

Secondly, we integrated the explanatory variables described in section Description and calculation of the explanatory variables into the model in order to find out whether these variables explain the differences between DTH and HEC. Therefore, it was hypothesised that the sum of all influencing factors can describe the percentage difference (perc) between HEC and DTH. Thus, we derived the following linear model:

$$
\operatorname{perc}=\beta_{0}+\beta_{1} \mathrm{bt} \_\mathrm{u}+\beta_{2} \mathrm{bt} \_\mathrm{a}+\beta_{3} \mathrm{f} \_\mathrm{t}+\beta_{4} \mathrm{sol}+\beta_{5} \mathrm{lw} \_\mathrm{z}+\beta_{6} \mathrm{age}+\beta_{7} \operatorname{size}+\varepsilon
$$

Owing to the fact that the internal heat gains depend on the usage of the building, and all subjects are residential buildings, this factor was dropped from the model. The ventilation loss is not included in the model either because it depends on the ventilation system and all buildings have the same 'system' (natural ventilation through windows).

\section{Strategy of model specification}

For the hypothesis $\mu_{D T H}=\mu_{H E C}$, we apply a mean comparison test ( $t$-test). For the second hypothesis, which tries to explain the differences, the dependent variable is the per cent deviation of the HEC and the DTH. We used the Akaike Information Criterion (AIC) for model comparison. As described in Wood (2006), selecting between (nested) models on the basis of which has a higher likelihood is generally unsatisfactory. The model with more parameters always has the higher likelihood, because each additional parameter allows the model to shift slightly closer to the observed data, by fitting the noise component of the data, as well as the signal. If we were to judge between models on the basis of their fit to new data, not used in estimation, then this problem would not arise. The AIC is an attempt to provide a way of doing this. Generally, we expect estimated models with lower AIC scores to be closer to the true model than those with a higher AIC score. We defined four linear models and compared them using the AIC. As it was our initial purpose to find out which of the parameters that describe the HEC according to the calculation methodology of DTH caused bias, all of them contain those five variables. These results can be used for an improved but basically unchanged calculation algorithm. Furthermore, we tried to include the age and the size of the building as additional explanatory variables, even if there should be no direct influence on the value of DTH from a theoretical point of view.

$$
\begin{array}{ll}
\text { A: } \text { perc }=\beta_{0}+\beta_{1} \mathrm{bt} \_\mathrm{u}+\beta_{2} \mathrm{bt} \_\mathrm{a}+\beta_{3} \mathrm{f} \_\mathrm{t}+\beta_{4} \mathrm{sol}+\beta_{5} \mathrm{lw} \_\mathrm{z}+\varepsilon & \mathrm{AIC}=284.901 \\
\text { B: } \text { perc }=\beta_{0}+\beta_{1} \mathrm{bt} \_\mathrm{u}+\beta_{2} \mathrm{bt} \_\mathrm{a}+\beta_{3} \mathrm{f} \_\mathrm{t}+\beta_{4} \mathrm{sol}+\beta_{5} \mathrm{lw} \_\mathrm{z}+\beta_{6} \mathrm{age}+\varepsilon & \mathrm{AIC}=283.508 \\
\text { C: } \text { perc }=\beta_{0}+\beta_{1} \mathrm{bt} \_\mathrm{u}+\beta_{2} \mathrm{bt} \_\mathrm{a}+\beta_{3} \mathrm{f} \_\mathrm{t}+\beta_{4} \mathrm{sol}+\beta_{5} \mathrm{lw} \_\mathrm{z}+\beta_{7} \operatorname{size}+\varepsilon & \mathrm{AIC}=282.424 \\
D: \text { perc }=\beta_{0}+\beta_{1} \mathrm{bt} \_\mathrm{u}+\beta_{2} \mathrm{bt} \_\mathrm{a}+\beta_{3} \mathrm{f} \_\mathrm{t}+\beta_{4} \mathrm{sol}+\beta_{5} \mathrm{lw} \_\mathrm{z}+\beta_{6} \mathrm{age}+\beta_{7} \operatorname{size}+\varepsilon & \mathrm{AIC}=281.281
\end{array}
$$

Surprisingly, size and age make a positive contributions to the model - consequently, we choose model ' $\mathrm{D}$ '. When analysing the scatter plot matrices of the several factors, we recognised that there are some conspicuous outlier candidates (eg Figure 2). 


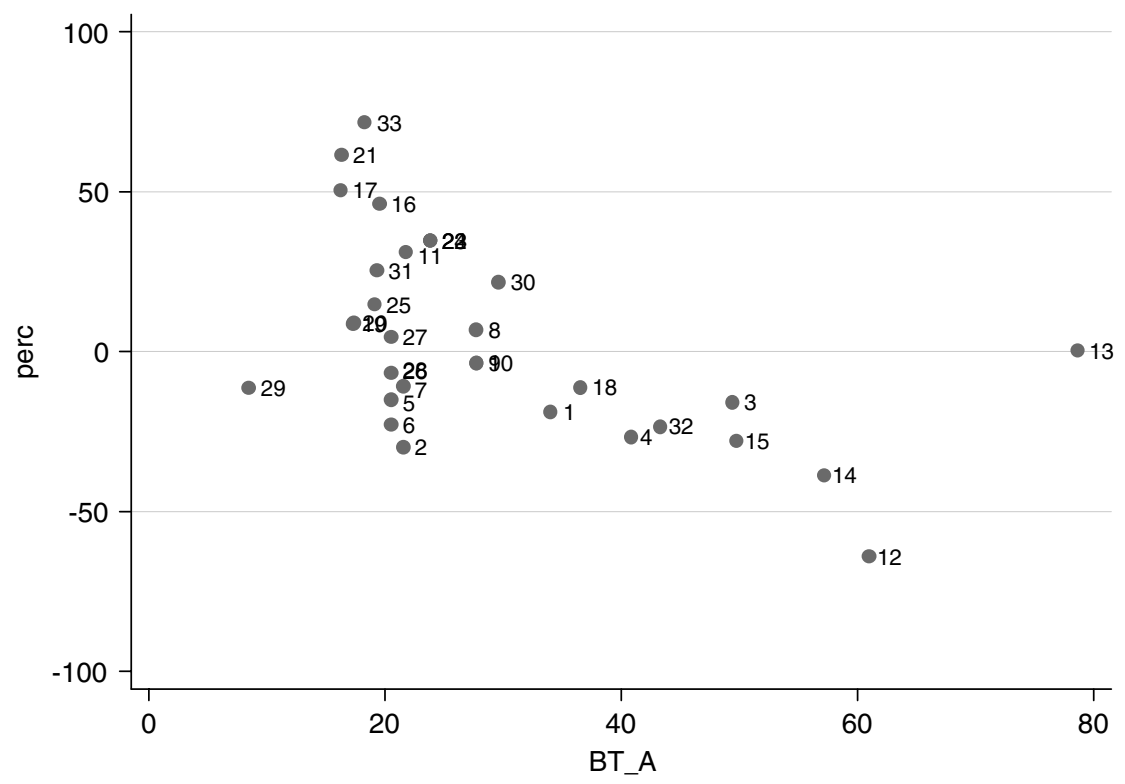

Figure 2: Example for an outlier candidate - here building no. 13

To find out whether those buildings are multivariate outliers (ie, which have a strong influence on the calculated coefficients), we used the method 'DFBETA' in STATA. This function first calculates a regression model. Then, the regression is calculated again, and one observation is dropped from calculation. The next step is to compare the two results to find out whether dropping out the subject has led to a huge difference in parameter estimation. If so, this observation has a great influence on the coefficients. This method is carried out for all observations (Kohler and Kreuter, 2006). Applying this function to our sample revealed that building no. 13 generally has a great influence (on all of the seven coefficients). Therefore, we excluded it from the sample. Buildings 12 and 20 were also peculiar (4 times), but because of the quite small sample we decided to retain them.

\section{RESULTS: MEAN COMPARISON TEST - HEC VS DTH}

As a matter of course, the theoretically calculated HEC and the practical collected DTH cannot always show the same value even if they are assimilated as described in the section Comparability of the DTH and HEC. This is due to different patterns of use and other individual factors that influence the energy consumption of buildings. Nevertheless, these factors should cancel out each other when comparing the means of HEC and DTH of a representative sample. In this study, we applied a $t$-test, which showed that there is no significant difference on comparing the means of HEC and DTH.

\section{RESULTS: ANALYSING THE DIFFERNCE BETWEEN HEC AND DTH}

The difference between HEC and DTH is displayed in the scatter plot of Figure 3 (left). The line demonstrates the ideal values of DTH and HEC (DTH=HEC). This scatter plot appears more or less uniformly distributed around this line. The second scatter plot in Figure 4 (right) shows the percentage difference between HEC and DTH. According to this diagram, it appears that buildings with a high DTH (low thermal quality) show an increasing tendency to have a negative percentage deviation (DTH $>$ HEC). This means that buildings that have a poor thermal quality in practice do not consume as much energy 

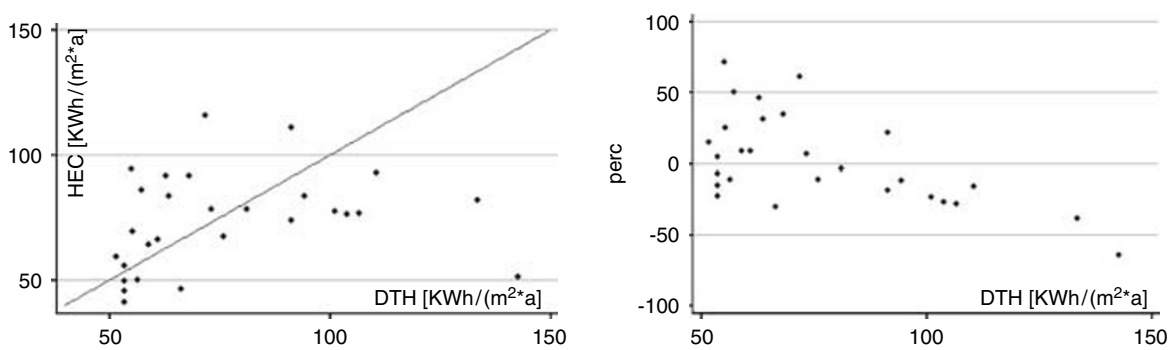

Figure 3: Direct comparison of HEC and DTH (left) and comparison of percentage difference and DTH (right)

as calculated. On the other hand, buildings with a high thermal quality show a slight tendency to be not as economical as the theoretical calculation indicates. For the further development of this study, more careful analysis with a larger sample needs to be carried out to be able to provide quantitative answers concerning this tendency.

Applying the model,

$$
\text { perc }=\beta_{0}+\beta_{1} \mathrm{bt} \_\mathrm{u}+\beta_{2} \mathrm{bt} \_\mathrm{a}+\beta_{3} \mathrm{f} \_\mathrm{t}+\beta_{4} \mathrm{sol}+\beta_{5} \mathrm{lw} \_\mathrm{z}+\beta_{6} \mathrm{age}+\beta_{7} \operatorname{size}+\varepsilon
$$

leads to the results shown in Box 1. The coefficients for the variables (first row) can be found in the second row, followed by the standard deviation, the $p$-value and the confidence intervals at a 5 per cent level of significance.

The whole model is highly significant as the F-statistic indicates, which indicates that the chosen variables can describe the difference between DTH and HEC. Consequently, the recommended way of calculating the variables may lead to biased estimations of HEC. In the following paragraphs, the explanatory variables and their influence on the deviation are described.

\section{Factors that show no effect on a reasonable level}

\section{Losses due to doors and windows $\left(f_{-} t\right)$}

These components show no significant effect on the difference between HEC and DTH. Even the scatter plot appears uniformly distributed, so that no tendency is observable (see Figure 4). Regarding the calculation of the DTH, this means that the methodology of calculating the losses through windows and doors does not cause bias.

\section{Age of the building (age)}

Here, the same applies as for the losses through doors and windows: no significant effect the scatter plot appears more or less uniformly distributed.

\section{Gains through solar radiation (sol)}

Looking at the scatter plot of 'sol', let us assume that there is a negative effect on the explained variable; however, this effect is not significant at a 10 per cent level - even if you drop the outlier candidates 12 and 14 (see Figure 4). A significant effect of these variables would mean that the gains due to solar radiation in practice are not as high as the calculation of the DTH for windows indicates. One possible explanation could be that the dwellers prevent solar radiation, because they have often shut their blinds; however, more careful analysis with a larger sample size remains to be carried out to prove this theory. 
sol_age_ft
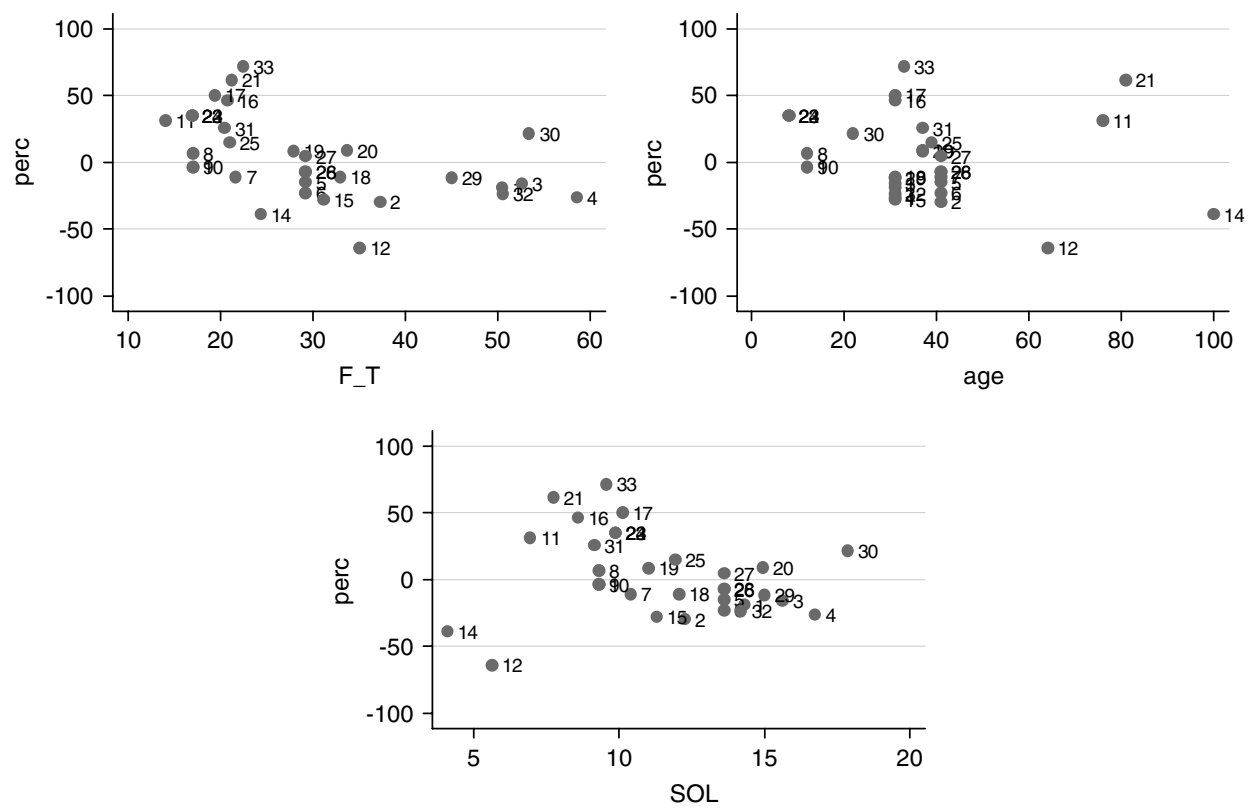

Figure 4: Effect of losses through windows/doors, solar gains and age on the percentage difference

\begin{tabular}{|c|c|c|c|c|c|c|}
\hline Source & SS & $d f$ & MS & & Number of obs & 32 \\
\hline & & & $\cdots-$ & & $F(7$, & 10.20 \\
\hline Model & 22208.051 & 31 & .57872 & & Prob > F & 0.0000 \\
\hline Residual & 7464.38152 & 24 & 015897 & & R-squared & 0.7484 \\
\hline$-\cdots-\cdots$ & $-\cdots-\cdots---$ & 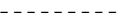 &.---- & & Adj R-squared & 0.6751 \\
\hline Total & 29672.4326 & 31 & 175244 & & Root MSE & 17.636 \\
\hline perc & Coef. & Std. Err & t & $P>|t|$ & [95\% Conf. & Interval] \\
\hline bt $u$ & -.9721277 & .4183359 & -2.32 & 0.029 & -1.835531 & -.1087249 \\
\hline$b t_{-}^{-} a$ & -1.186209 & .4366071 & -2.72 & 0.012 & -2.087322 & -.2850961 \\
\hline$f \_t$ & .535222 & .6856628 & 0.78 & 0.443 & -.8799164 & 1.95036 \\
\hline sol & -1.296503 & 3.295084 & -0.39 & 0.697 & -8.097221 & 5.504215 \\
\hline lw_z & 10.26396 & 4.351101 & 2.36 & 0.027 & 1.283729 & 19.24419 \\
\hline age & .4457949 & .2832841 & 1.57 & 0.129 & -.1388748 & 1.030465 \\
\hline size & -.0025751 & .0013988 & -1.84 & 0.078 & -.0054621 & .0003118 \\
\hline _cons & 35.56147 & 51.73648 & 0.69 & 0.498 & -71.21737 & 142.3403 \\
\hline
\end{tabular}

Box I: Example results of model

\section{Factors that are significant at a 10 per cent level}

\section{Size of the building (size)}

The size of the building (gross floor area) is significant at a 10 per cent level. The analysis shows a negative coefficient, which means that the difference declines the larger the building is (Figure 5). If you compare two similar buildings, one $1,000 \mathrm{~m}^{2}$ larger than the other, the difference is expected to decline by 2.6 per cent (per cent points). At first glance, this does not sound like much, but the energy certification is applicable for detached houses as well as for large blocks of flats. When applying the energy certification to a detached house of, for example, $200 \mathrm{~m}^{2}$ in contrast to a block of flats of $10,200 \mathrm{~m}^{2}$, the result of the DTH calculation of the one-family house is expected to be nearly 26 per cent higher than for the huge residential building. 


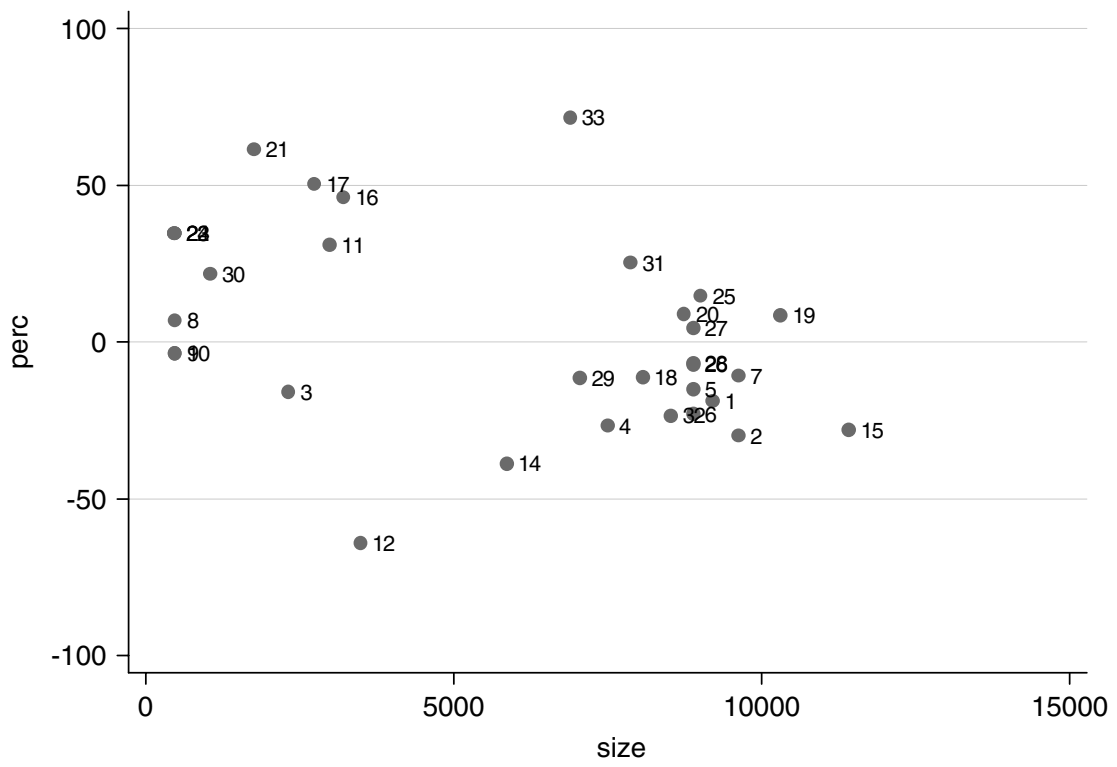

Figure 5: Effect of building size on the percentage difference

\section{Factors that are significant at a 5 per cent level}

\section{Components that adjoin cold air/cold ground (bt_a)}

As already mentioned, this variable describes the walls and slabs that adjoin the outside. These factors have a negative coefficient of 1.19. To make it more tangible you can say that the difference is expected to decline by 11.9 per cent, when you compare two similar buildings whereas one has calculated losses through components to the outside of $10 \mathrm{kWh} /\left(\mathrm{m}^{2} \mathrm{a}\right)$ and the other $20 \mathrm{kWh} /\left(\mathrm{m}^{2} \mathrm{a}\right)$. For the algorithm of the DTH this tells us that the corresponding components with a poor thermal quality are not that 'bad' in practice as the theoretical calculation indicates. The components with a high thermal quality, however, are not as economical in energy consumption as their calculated DTH demonstrates. The reasons for these effects are not yet clear and need to be further investigated.

\section{Components that adjoin unheated rooms (bt_u)}

Here the same applies as for the components to the outside. The only difference is a lower effect ( -0.97 per cent) of this factor, which means that the calculation of these parts biases the difference to a lesser extent.

\section{Loss due to thermal bridges (Iw_z)}

For these components, a positive effect is estimated: one additional $\mathrm{kWh} /\left(\mathrm{m}^{2} \mathrm{a}\right)$ of losses through these components leads to an increase of the difference of 10.26 per cent. This, of course, causes a large bias when comparing the calculated losses to the real losses through these components. In the case that this result can be corroborated when testing a larger sample, there is a huge need to scrutinise the methodology of calculating these kinds of losses. Presumably, the losses through these parts are underestimated in general and need to be considered in the calculation in a different way. The scatter plot (Figure 6) shows that there are many buildings, where no losses through thermal bridges are calculated — this also seems somehow questionable. 


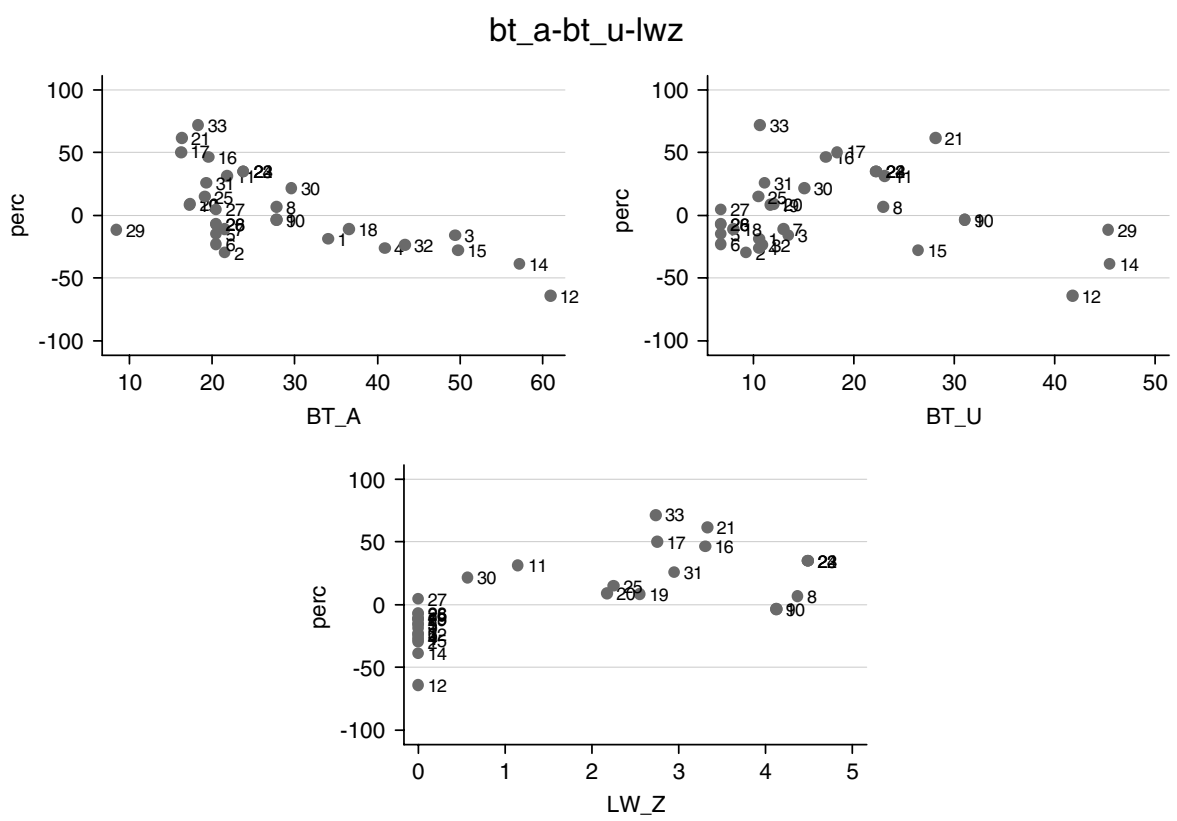

Figure 6: Effect of losses through components to the outside, compared to unheated rooms and losses through thermal bridges on the parentage difference

\section{CONCLUSION}

This paper is the first contribution to a study where we try to identify and quantify the reasons for the gap between the theoretically calculated heating energy demand and the measured HEC of buildings. Therefore, we applied a linear regression model based on data from 33 multifamily houses in Austria. It reveals that the size of the building leads to a decline of the deviation: the gap between practical consumption and theoretical demand is expected to decline by 2.6 per cent if you compare two similar buildings, one $1,000 \mathrm{~m}^{2}$ larger than the other. Components such as external walls, ceilings and roofs also lead to a biased result: the components with a theoretically poor thermal quality are expected not to be that 'bad' in practice as the theoretical calculation would lead us to believe. On the contrary, the buildings with a building shell of high thermal quality are not that economical in practice as the theoretical results would indicate. The same effect is estimated for the components that adjoin unheated rooms, but with a lower effect. Moreover, losses due to thermal bridges also show a significant effect. For these components, a positive influence is estimated which means that one additional $\mathrm{kWh} /\left(\mathrm{m}^{2} \mathrm{a}\right)$ of losses through these components leads to an increase of the difference of 10.26 per cent. The results of this paper should be kept in mind when interpreting the key figures of the energy certification in practice.

\section{Notes}

1 In the following sections, $\mathrm{HEC}$ is used synonymous to the adjusted heating energy consumption $\left(H E C_{a d j}\right)$.

2 Individual accounting generally leads to lower consumptions.

\section{References}

Cerveny, M., Lang, G., Lutter, E. and Tretter, H. (2004) Rechnerischer Heizwärmebedarf und tatsächlicher Heizwärmeverbrauch in thermisch optimierten Wohnbauten, Energie Verwertungsagentur, Wien. 
DENA (2005) Energiepass für Gebäude: Evaluation des Feldversuchs, Deutesche Energie-Agentur, Karlruhe. EPBD (2002) Directive 2002/91/EC, The European Community Official Journal, no. L 001, 04/01/200, Brussles. Hegner, H.-D. (2004) Energieausweise für Deutschland - ein neuer Sachstand Bundesbaublatt, Bundesministerium für Verkehr, Bau- und Wohnungswesen, Berlin.

Kohler, U. and Kreuter, F. (2006) Datenanalyse mit Stata, R. Oldenburg Verlag, München-Wien.

OIB (2004) 'Programm für die Berechnung von Energiekennzahlen', www.oib.or.at Österreichisches Institut für Bauphysik, Wien, Accessed 12th February, 2007.

OIB (2005) Leitfaden Energietechnisches Verhalten von Gebäuden, Österreichisches Institut für Bauphysik, Wien. Schöngrundner, K. (2002) Heizgradtagbereinigung des Heizenergieeinsatzes, Magistrat der Stadt Graz, Graz.

Vornorm ÖNORM H 5056-1 (2004) Heizungsanlagen mit oder ohne Warmwasserbereitung (energy demand of heating systems with or without domestic hot water), Österreichisches Normungsinstitut, Wien.

Wood, S. (2006) Generalized Additive Models: An Introduction with R, Chapman \& Hall/CRC, Boca Raton.

ZAMG (2006) Heizgradtage auf Gemeindebasis, Zentralanstalt für Meteorologie und Geodynamik, Wien. 